\section{Experimental data on authority of source bias in decision making}

\section{Pier Luigi Baldi}

\section{Department of Psychology, Catholic University of the Sacred Heart, Milan, Italy}

\section{Dear Editor,}

The psychological approach to reasoning and decision making has shown i) the restricted cognitive resources available to people (see for example, the notion of bounded rationality by Simon ${ }^{1}$ ); ii) the inferential errors attributable, at least partly, to limited working memory capacity ${ }^{2}$; iii) the use of heuristics, i.e. strategies which allow saving cognitive resources by simplifying elaboration yet at the risk of biases, etc. These errors, or distortions, do not appear to be negligible but rather important and recurring behavioral anomalies. ${ }^{3,4}$ Moreover, since 1950s several psychological studies have highlighted the role of emotions in decision making, a role that has been evidenced also by the neurosciences. ${ }^{5}$

The three experimental studies presented here were aimed to evaluate the influence of authority of source on decision making, each one examining the following fields: logic, grammar, and figurative art.

In the first experiment, 120 university students were administered the three questions of the Cognitive Reflection Test and a fourth question of logic; they were provided with the answers (all of which deliberately wrong) and were asked to express whether they agreed with them. The experimental group was told that the answers had been given by a mathematics teacher; the control group was told that the answers had been given by students with some difficulties in mathematics.

In the second experiment 90 university students were administered five pairs of sentences; one sentence in each pair was grammatically correct, the other was wrong. The experimental group was required to evaluate the exactness of the answers (all of which wrong) given by a non-existent grammar teacher; the control group was required to indicate the exact sentence in each pair.

In the third experiment, 60 participants were shown five pairs of pictorial reproductions; only one reproduction in each pair was of great artistic value. The experimental group was asked to accept or reject the judgements (all of which wrong) of a non-existent art critic; the control group was asked to indicate the picture deemed most valuable in each pair.

In conclusion, statistical analysis, conducted through the $\chi^{2}$ test, has shown a significantly higher number of errors in the experimental group than in the control group all through the three experiments. The results emphasize the conditioning exerted by a source considered to be authoritative on the decision-making process of participants.

\section{References}

1. Simon HA. Models of bounded rationality.
Correspondence: Pier Luigi Baldi, Department of Psychology, Catholic University of the Sacred Heart, largo Gemelli 1, 20123 Milan, Italy. Tel. +39.02.7234.2284 - Fax: +39.02 .7234 .2280 . E-mail: pier.baldi@unicatt.it

Key words: authority of source, bias, decision making.

Conflict of interests: the author declares no potential conflict of interests.

Received for publication: 26 September 2013. Accepted for publication: 26 September 2013.

This work is licensed under a Creative Commons Attribution 3.0 License (by-nc 3.0).

(C) Copyright P.L. Baldi, 2013

Licensee PAGEPress, Italy

Emergency Care Journal 2013; 9:e24

doi:10.4081/ecj.2013.e24

Cambridge, MA: The MIT Press; 1982.

2. Johnson-Laird PN, Byrne RMJ, Schaeken W. Propositional reasoning by model. Psychol Rev 1992;99:418-39.

3. Tversky A, Kahneman D. Judgment under uncertainty: heuristics and biases. Science 1974;185:1124-31.

4. Kahneman D, Slovic P, Tversky A. Judgment under uncertainty: heuristics and biases. New York: Cambridge University Press; 1982.

5. Damasio AR. Descartes' error: emotion, reason, and the human brain. New York: Avon; 1994. 